\title{
How does risk mediate the ability of adolescents and adults with intellectual and developmental disabilities to live a normal life by using the Internet?
}

\author{
Jane Seale ${ }^{1} \&$ Darren Chadwick ${ }^{2}$ \\ ${ }^{1}$ Open University, Milton Keynes, UK \\ ${ }^{2}$ University of Wolverhampton, Wolverhampton, UK
}

\begin{abstract}
The focus of this position paper is Internet use by adolescents and adults with intellectual and developmental disabilities. Drawing on existing literature in the field we will identify problems with and gaps in the current research. Our review is framed by three main questions: What constitutes a 'normal' life for adolescents and adults with intellectual and developmental disabilities? What constitutes 'normal' use of the Internet for adolescents and adults with intellectual and developmental disabilities? How does risk mediate the ability of adolescents and adults with intellectual and developmental disabilities to live a normal life by using the Internet? The key focus of this review is the complex relationship between adolescents and adults with intellectual and developmental disabilities and those providing support; how they negotiate access to and use of the Internet and how perceptions regarding risk and normalcy mediate this negotiation. As a result of this review we will argue that identified gaps and problems in the research field need to be addressed by expanding both methodological and conceptual approaches. In particular we will propose the need for more in-depth qualitative research that is inclusive in nature. We will also propose that an adapted positive risk-taking framework might be useful in framing the design, implementation and analysis of future research.
\end{abstract}

Keywords: intellectual and developmental disabilities; adolescents; adults; Internet; digital inclusion; risk; positive risk-taking

\section{Introduction}

The focus of this position paper is Internet use by adolescents and adults with intellectual and developmental disabilities (IDD). This is a field that the authors have spent the past fifteen years researching. The first author was one of the first researchers to explore whether and how the Internet enabled people with IDD to express their sense of identity and belonging (Seale, 2001; Seale \& Pockney, 2002). This work led her to examine the role that parents and carers play in facilitating Internet use and the extent to which their perceptions regarding risk and potential present barriers to both access and use of the Internet (Seale, 2014). The second author has conducted inclusive research with people with IDD and participatory research with family carers of people with IDD in Ireland. This work highlighted the important role those in the social environment have on the wellbeing and life experiences of people with IDD and the ways in which the desires and wishes of these groups exist in tension with each other. Recently he has turned his attention to online inclusion of people with learning disabilities and the factors that can influence this (see for example, Chadwick, 2016; Chadwick \& Wesson, 2016). 
The aim of this paper is to review current research and practice in the field with a view to identifying areas that require further investigation as well as to suggest conceptual or theoretical lenses can might be usefully be used to frame future research. For the purposes of this paper, the Internet is understood to include general use of the World Wide Web and email as well as more specific uses such as social media (e.g. Facebook and Flickr) and virtual worlds (e.g. Second Life). The term IDD has a wider international use than associated terms such as learning disabilities or learning difficulties. However definitions can vary depending on factors such as country; context (e.g. medical, social or education) and stakeholder groups (e.g. researcher, practitioner, carer or selfadvocate). Therefore, recognising that the papers we draw on in our review all vary to some extent in their understanding of IDD, for the purposes of this paper we propose to adapt the definition of learning disabilities offered by Seale, Nind, and Simmons (2013, pp. 1-2) to argue that people with IDD: "are deemed to have some form of difficulty with experiencing and acquiring new information. Secondly, this difficulty is described as starting in childhood. Thirdly, the difficulty is said to impact on people's ability to cope independently." Such a definition would include people who are categorised with labels such as Autism and Down Syndrome but exclude those who are labelled as having specific learning difficulties such as dyslexia.

Our review of the literature will be underpinned by three key questions:

1. What constitutes a 'normal' life for adolescents and adults with IDD?

2. What constitutes 'normal' use of the Internet for adolescents and adults with IDD?

3. How does risk mediate the ability of adolescents and adults with IDD to live a normal life by using the Internet?

It is our contention that addressing these three questions is pivotal to understanding what influences Internet use by people with IDD and raises important questions in relation to inclusion, rights, participation, equity and social justice.

\section{Method}

In reviewing the literature on risk, Internet use and people with IDD we have undertaken what Grant and Booth (2009) describe as a critical review; where a critical review is understood as one that undertakes an extensive but not exhaustive review of the literature in order to critically evaluate the identified studies. Our choice of review method does not reflect a rejection of the methods used in more systematic literature reviews, but rather we considered that a critical review approach would be more appropriate given the current state of play in this field and our intentions regarding the purpose of the review.

With regards to the current state of play of research in the field of risk, Internet use and people with IDD it is our contention that this field is so under-researched that applying rigid exclusion criteria would run the risk of excluding papers that could make a useful contribution to debate in this underdeveloped field. In light of this, drawing on our expertise and knowledge of the field, we have tried to be as inclusive as possible in the literature we have included in our review. The papers cited therefore present and synthesise the material gathered as part of previous reviews that the authors have conducted (see for example Seale, 2014; Chadwick, Fullwood, \& Wesson, 2012; Chadwick, Wesson, \& Fullwood, 2013) and more recent conference papers, journal papers and book chapters located through searching broad databases such as Scopus and ResearchGate. The review also includes work that describes practice as well as more empirically based work. In order to provide a focus, we have, with just a few notable exceptions, excluded literature that relates solely to the use of the Internet by children (under the age of 13) with IDD. Some of the studies reviewed included participants who were both under and over 13 and we have included these. The field of risk, Internet use and people with IDD is also multidisciplinary with papers being published in a vast array of different journals including education journals; medical, therapeutic and rehabilitation journals as well as technology and informatics specific journals. In recognition of this multidiscipinarity, we felt it appropriate to take a diverse approach to the keyword terms used to search for relevant literature. For example, in searching for papers relevant to IDD we used a range of terms including: learning difficulties, learning disabilities, intellectual impairment and lifelong impairment. In searching for papers relevant to the Internet we were mindful of the fact that a range of terms are used including websites, home pages, information and communication technologies, social networking sites, virtual worlds, blogging and cyber-bullying. 
With regards to the intended purpose of the review, the aim of our review was to critically evaluate the found literature in order to propose new ways of conceptualising the field that may provide what Grant and Booth (2009, p. 93) call a 'launch pad' for a new phase of research and methodological development. Rather than seeking to find answers or solutions in the way that a systematic review might do; we aim is to identify issues and questions and provide a framework for future work, which may in time provide more complete answers or solutions.

As this review paper does not involve primary data collected from human participants, ethical approval was not sought. Nevertheless, we acknowledge that empirical research in this field raises complex ethical issues which require careful consideration. Consideration of these is outside of the scope of this review; but could usefully be explored in future research work.

We have organised our review of the literature around the three questions outlined in the introduction and in discussing the issues raised from this review we will draw parallels with other related fields such as digital inclusion and Internet use by children and young children.

\section{What Constitutes a Normal Life for People With Intellectual and Developmental Disabilities?}

Reading across the literature from the IDD field and literature from the digital inclusion field, leading a 'normal' life involves taking risks; being digitally included (i.e. accessing the Internet) and being able to exercise the same human rights as non-disabled people (being enabled to access the Internet).

\section{A Normal Life Involves Taking Risks}

Since the 1970's and the move towards 'normalization' (Wolfensberger, Nirje, Olansky, Perske, \& Roos, 1972), researchers and practitioners have been grappling with what kind of life they should be striving to enable people with IDD to live. The phrase often used is: 'as normal a life as possible'. But what constitutes normal? For most, the vision is to enable people with IDD to live independently. But with independent living, comes risks; risks that non-disabled people take for granted. The risk of getting run over when you cross the road, the risk of forgetting to lock the front door and being burgled as a consequence, the risk of forgetting to turn the gas off after cooking a meal and so on. For non-disabled people everyday risks do not normally prevent them from leaving the house, cooking a meal or crossing the road. Taking risk is a 'normal' and a natural part of everyday life.

In the field of IDD there have been attempts to embed risk into support practices. Perske (1972, p. 195) for example, argued that experiencing 'the risk-taking of ordinary life' is necessary for human growth and development'. The Jay Committee Report on Mental Handicap Nursing and Care in England argued back in 1979 that 'mentally handicapped people' needed to assume a 'fair and prudent share of risk (Jay 1979, para. 121). In the earlier part of this decade the UK Department of Health attempted to encourage the development of positive risk taking within health and social care practice. Positive risk-taking is generally understood as enabling people with IDD to have greater control over the way they live their lives, which may bring benefits in independence and well-being, but may also involve an element of risk either in terms of safety or in a potential failure to achieve the intended goal. Positive risk-taking stresses managing risk not avoiding or ignoring it; taking positive risks because the potential benefits outweigh the potential harm (Alaszewski \& Alaszewski, 2002; Morgan, 2004). Central to the concept of positive-risk taking is the notion that it involves a shared decision-making and negotiation process between people with IDD and their support workers (e.g. parents, carers, teachers, social workers). In supported decision-making the 'risks of independence for individuals are shared with them and balanced openly against benefits' (Department of Health, 2005, p. 10). Despite policy goals for an 'ordinary life' which one might assume to be a life involving risks, positive risk taking does not have a strong history of being embedded in the culture and practice of support services for people with IDD.

Seale et al. (2012) have expanded the positive-risk taking framework to include the concept of creativity (more specifically possibility thinking) and resilience. They argue that support workers need to balance the 'what if something goes wrong' questions with 'what if something goes right' questions. Here possibility thinking is not about ignoring the big risks associated with something going wrong; but about giving space to consider the big benefits, if the proposed action goes right. Taking risks however can take support workers, outside of their 
comfort zone, which might be stressful. Responding to this stress in order to maintain and develop long-term successful positive risk-taking practices may therefore require resilience. Seale et al. (2012) drew on the work of Goodley (2005) who does not view resilience as a personal characteristic but as a political response to disabling and disempowering circumstances. Whilst Goodley views resilience as optimistic because it encourages supporters, professionals, researchers and policy makers to assume that people with learning difficulties have the potential for resilient lives he also views resilience as an indicator of disablement because 'displays of resilience' (p.334) capture the wider exclusionary environment in which they have to be made. In the context of this paper, an exclusionary environment is one in which people with IDD have been prevented from deciding what kind of life they would like to live; what living a normal life means for them.

\section{A Normal Life Is One Where People With Intellectual and Developmental Disabilities Are Digitally Included}

If we take a normative approach and look at what constitutes a normal life for non-disabled people, then there is a strong argument within the digital inclusion literature that technology use is central to everything we do, and therefore central to living a normal life and our inclusion in society. Digital inclusion happens when all members of society are able to access the affordances offered by technology use (Selwyn \& Facer, 2007). Some researchers have identified that people with IDD are one of the groups in society which is unable to access the affordances of technologies and are therefore at risk of marginalization and not being able to live a 'normal' life:

As everyday living continues to involve increased use of digital technologies, people who cannot use ICT will become more noticeably disadvantaged. This digital disadvantage will continue to grow as the mainstream population increases its use of ICT and people with developmental disabilities do not. (Moisey \& van de Keere, 2007, p. 78)

Despite this identification, disability tends to be treated as a homogenous group within mainstream digital inclusion research, which means that IDD are rarely specifically focused upon (Chadwick et al., 2012). This invisibility is concerning and raises important questions regarding whether people with IDD are being denied a 'normal' life and whether they are able to exercise the same human rights as non-disabled people.

\section{A Normal Life Is One Where People With Intellectual and Developmental Disabilities Can Exercise the Same Human Rights as Non-Disabled People}

Underpinning the digital inclusion agenda is a human rights agenda incorporating a desire for social justice via equity of treatment of disadvantaged groups, with the aim to reduce the 'digital divide' and enhance wellbeing. Exercising and being afforded the same rights as people without IDD appears evidently challenging for society, people with IDD and those who support them. There have been moves towards taking a human rights perspective to enhance digital inclusion for people with disabilities more generally (Jaeger, 2015). Taking the USA as an example, Jaeger argues that despite an increase in literature and work in this area this has not been accompanied by an increase in accessibility, digital inclusion and equality in the lives of people with disabilities. He advocates political lobbying and legal change alongside the acknowledgment of digital accessibility as a human rights issue as a route to better enable real online equality to manifest.

There has also been recent work investigating specific articles from the United Nations Convention on the Rights of Persons with Disabilities (UNCRPD, 2006) in different aspects of the lives of people with IDD, for example, Article 19, The right to be included within the community (e.g. Milner \& Mirfin-Veitch, 2012) and Article 12, The right to equal recognition before the law (e.g. Watson, 2016). However research considering the UNCRPD specifically in relation to the digital inclusion of people with IDD is still largely absent. With regard to the applicability of specific articles contained within the UNCRPD to the issues addressed within this paper, Article 9 of the convention focuses on Accessibility, with the aim of enabling "persons with disabilities to live independently and participate fully in all aspects of life" pertains directly to digital inclusion. As the digital world forms an increasing aspect of people's normal everyday lives, so equal access to the digital world by all members of society arguably becomes a human rights issue. However the cross-cultural implementation of this article of the convention by member countries has yet to be fully articulated and explored in relation to digital inclusion of people with IDD. 
As essential aspects of everyday life have become increasingly intertwined with technology and technology access (i.e. education, employment, social interaction, civic participation etc.), self-determination and support for digital inclusion has become more fundamental. Accessing information via technology and self-determination over what to access in the digital world are encapsulated with Article 21 of the UNCRPD, "Freedom of expression and opinion, including freedom to seek, receive and impart information and ideas on an equal basis with others and through all forms of communication of their choice, as defined in article 2 of the present Convention." (n.p.) More empirical exploration of the ways in which these articles are enacted by those developing technologies and the political, legal, social, cultural and economic systems influencing the ability of people with IDD to take up and control what information and activities they access in the digital world is needed. This also necessitates researching the day-to-day supports received around Internet use and the ways online freedom of expression and access are negotiated, permitted and curtailed.

\section{What Constitutes ‘Normal’ Use of the Internet?}

In the mainstream digital inclusion literature normal use of technology and the Internet is equated with motivated, meaningful and appropriate use. Our review of the literature suggests that limited attention has been paid to these issues in relation to people with IDD.

\section{Normal Internet Use is Motivated Use}

In the mainstream digital inclusion literature there is much talk about 'motivating' the digitally excluded to use technology and the Internet (British Educational Communications and Technology Agency (BECTA), 2001). This talk of needing to motivate users and raise aspirations is repeated to a much lesser extent in the IDD field. For example Zubal-Ruggieri (2015, p. 211) argues: "We need to continue to work on technological access and literacy for self-advocates and all people with disabilities, but we also need to teach people how this technology can be used to change their lives." Some researchers have observed how motivated some people with IDD are to use the Internet; but the descriptions of how this motivation manifests itself are quite vague. Nevertheless an emergent pattern of motivation can be discerned. Carey, Friedman, and Bryen (2005) and Moisey and van de Keere (2007) both report on how participant interest in using the Internet was high as reflected by eagerness to spend extra time using it. Schindler and Borchart (2001) and Rocha, Bessa, Magalhaes, and Cabral (2015) refer to how the people with IDD they worked with tried hard and were determined to complete tasks. While Näslund and Gardelli (2013) and Williams (2011) observe examples of being confident to experiment or self-teach. What needs further investigation is the extent to which such motivation is linked to specific uses of the Internet. For example, in the field of sensory impairment Vanden Abeeele, de Cock, and Roe (2012) applied the ideas of Katz, Blumler, and Gurevitch (1974) and Ruggerio (2000) regarding the uses and gratification theory and engagement with Computer Mediated Communication to identify that the most common motivations for usage of the Internet amongst research participants with sensory impairment was information-seeking and communication with friends/family.

In our review of the literature (See Table 1) we have identified that the Internet is being used by people with IDD in six main ways, ranging from learning new skills to Internet dating. A closer inspection however reveals that the nature of use varies depending on the level of mediation by powerful others such as researchers or support workers. Learning a specific skill online appears to be much more mediated than Internet dating. This raises important questions such as are people with IDD equally as motivated to use the Internet when it is highly mediated by others, compared to less mediated uses?

\section{Normal Internet use is Meaningful Use}

Näslund and Gardelli (2013) argue that when a person with IDD is motivated to use the Internet they are motivated to act and use their abilities in a way that is meaningful to them, thus linking Internet use to concepts of active participation and meaningful use. In mainstream digital inclusion research, meaningful use has been associated with 'smart use' or use that is relevant and has some 'fit' with a person's life (Selwyn, 2006; Selwyn \& Facer, 2007). To date there has been little in-depth consideration of what constitutes meaningful or appropriate use for people with IDD. 
Table 1. Examining the Mediation of Internet use across Different Internet Activities.

\begin{tabular}{|c|c|c|c|}
\hline & $\begin{array}{l}\text { Mediated by researcher } \\
\text { (special funded project } \\
\text { where Internet use is an } \\
\text { evaluated 'intervention') }\end{array}$ & $\begin{array}{l}\text { Mediated by those } \\
\text { providing more formal } \\
\text { support (e.g. teacher, } \\
\text { librarian, parent) }\end{array}$ & $\begin{array}{l}\text { Independent (perhaps } \\
\text { with some element of } \\
\text { informal peer support or } \\
\text { mentorship) }\end{array}$ \\
\hline $\begin{array}{l}\text { Learning a specific } \\
\text { skill such as cooking, } \\
\text { social skills }\end{array}$ & $\begin{array}{l}\text { Alquatani \& Schoenfield } \\
2014\end{array}$ & $\begin{array}{l}\text { Butler \& Bayne } 2000 \\
\text { Schindler \& Borchardt } \\
2001\end{array}$ & \\
\hline Information-seeking & Williams 2006 & Johnson \& Hegarty 2003 & Näslund \& Gardelli 2013 \\
\hline $\begin{array}{l}\text { Identity - } \\
\text { presentation and } \\
\text { management }\end{array}$ & McClimens \& Gordon 2009 & Seale 2001 & $\begin{array}{l}\text { Bannon et al. } 2015 \\
\text { Holmes \& Loughlin } 2014\end{array}$ \\
\hline $\begin{array}{l}\text { Social connectedness, } \\
\text { belonging community }\end{array}$ & $\begin{array}{l}\text { Kydlund, Molka-Danielson, } \\
\text { \& Balandin } 2012 \\
\text { Moisey } 2001 \\
\text { Moisey \& van de Keere } \\
2007 \\
\text { Stendal et al. } 2011\end{array}$ & & Bannon et al. 2015 \\
\hline Friendship & $\begin{array}{l}\text { Hegarty } 1998 \\
\text { McClimens \& Gordon } 2009\end{array}$ & Seale \& Pockney, 2002 & $\begin{array}{l}\text { Holmes \& O'Loughlin } 2014 \\
\text { Näslund \& Gardelli } 2013 \\
\text { Löfgren-Mårtenson } 2008 \\
\text { Shpigelman \& Gill } 2014\end{array}$ \\
\hline Dating/Sex & $\begin{array}{l}\text { Löfgren-Mårtenson et al. } \\
2015\end{array}$ & & $\begin{array}{l}\text { Holmes \& O'Loughlin } 2014 \\
\text { Löfgren-Mårtenson } 2008 \\
\text { Buijs et al. } 2017\end{array}$ \\
\hline
\end{tabular}

Stendal, Molka-Danielson, Munkvold, and Balandin (2011) report on a project that supported people with IDD to use Second Life. They report that the aim of the project was to discover if virtual worlds help participants to engage in meaningful activities. They don't define what they or their participants understand by meaningful or what constitutes evidence of meaningful use. Instead they offer vague uncritical reports such as:

Generally all the participants express joy and excitement about spending time in the virtual world (p. 112)

The freedom [through being able to fly through the virtual world] this represents seems to be of great importance in the virtual world (p. 112)

Creation of friendships between avatars has been pointed at by the participants as important (p. 114)

Moisey and van de Keere (2007, p. 89) claim that going online is meaningful for people with IDD. However, they choose to understand a meaningful activity as one that: "someone without a disability would also do". This suggests that perceptions of meaningful use will be mediated by others. In Moisey and van de Keere's quote, it is the wider non-disabled society, but it may also be parents, carers and support workers. We argue therefore that it is important to examine in more detail the potential tensions inherent in understanding and negotiating meaningful use of the Internet.

\section{Normal Internet Use is Appropriate Use}

'Normal' engagement with the digital world could be viewed as what is typically and commonly happening in a particular context on a regular basis, i.e. all digital behavior that is occurring is normative. Alternatively, it could be seen as equating to what is considered societally to be normative use, in other words what is morally or legally 'correct' or appropriate use. In this second view what is normal corresponds with what is appropriate, and probably aligns more closely with typical prosocial and benign online activities (e.g. information seeking, keeping in contact with friends and family). However, when discussing engagement with the digital world there are also regularly occurring patterns of Internet use which include those which are 'unlawful' and those labeled as 
'harmful', 'risky' or 'antisocial', which may be considered less appropriate. For example there is a large body of literature focusing on Internet addiction or 'problematic Internet use' (e.g. Davis, Flett, \& Besser, 2002; Turel \& Serenko, 2012).

There are moral judgements here intertwining with judgements of what is 'normal'; which raises the issue of what behaviors are 'normal' or appropriate for people with IDD. For example, in a qualitative account reported by Chadwick (2016) a person with mild IDD was concerned about downloading viruses and how to protect himself from this; but illegal downloading was clearly common practice amongst his non-disabled family and his friends. This was clearly a behavior that he had control over and wanted to engage in. He also talked about finding out how to make a virus and putting it on his father's computer as a joke. Here we have common behavior that could be considered antisocial but that the person clearly self-determined that he wished to engage in. This example highlights the need to examine the nuances of online practices by people with IDD; the potential gradation within 'risky' online behavior and the competing conceptualizations that surround the notion of normal or appropriate online engagement.

\section{How Does Risk Mediate the Ability of People With Intellectual and Developmental Disabilities to Live a Normal Life by Using the Internet?}

Many factors are known to influence the ability of people with IDD to live a 'normal' life and use the Internet. Two factors that are frequently discussed in the literature are accessibility problems (Carey et al., 2005; Rocha et al., 2015) and the levels of digital literacy possessed by people with IDD (Moisey \& van de Keere, 2007; Jerome, Frantino, \& Sturmey, 2007). In the context of our review however, we will explore in more detail how risk mediates the ability of people with IDD to live a normal life. Specifically we will explore perceptions of Internet risk and perceptions regarding appropriate risk intervention strategies.

\section{Perceptions of Internet Risk}

When thinking about how perceptions of risk might influence use of the Internet by people with IDD two key areas emerge: perceptions that Internet use is risky and perceptions that people with IDD are a vulnerable, 'atrisk' population. Whilst these two clearly intersect, we will deal with each separately.

Drawing together the potential benefits and risks of Internet use, Livingstone and Haddon (2009) proposed a conceptual model drawn from their study of young people across Europe, with primary online risks including:

- Conduct - engagement in antisocial behavior in relation to Internet use and ICT (e.g. illegal downloading, bullying, uploading sexually inappropriate pictures or text, addictive and compulsive online behavior to the extent that other positive life opportunities are missed out),

- Contact - negative contact online (e.g. having personal information stolen, being bullied, being groomed, unwelcome persuasion) and

- Content - exposure to harmful, manipulative or exploitative content (e.g. a violent or hateful material, harmful sexual material, extremist or racist information, inappropriate commercial advertising, marketing schemes or hidden costs)

Livingstone, Mascheroni, \& Staksrud (2015) revised this model and identified a positive correlation between risks and opportunities. They suggest that exposure to opportunities brings with them exposure to increased risk and that efforts to reduce risk may also reduce opportunities. They also report that exposure to more risks is not necessarily associated with greater reported harm. Chadwick, Quinn, and Fullwood (2017) have attempted to adapt Livingstone and Haddon's original model to IDD. We would argue however, that this work needs to be developed further so that any model of online risks is derived from data drawn directly from adults with IDD (as opposed to non-disabled young people). It is likely that more qualitative approaches will be needed in order to illuminate the complex relationships between use, risk and meaningfulness that our review of the literature suggests is required. For example, despite some online behaviors being labeled as inappropriate or 'risky' this does not necessarily equate with them being meaningless. Engagement in risky behaviors could be exceedingly meaningful for adults with IDD in terms of their development of knowledge, skills, independence and resilience. 
Concerns over risk of Internet use is not unique to people with IDD. However, for some, people with IDD are deemed to be at particular risk. For example, Shpigelman and Gill (2014) suggest that the risks of using Facebook and in particular in the risk of loss of privacy may pose an even greater risk to people with IDD than the general population; while Plichta (2011) argues that a combination of the characteristics of modern technology, the limited social skills of people with IDD, their perceived lack of successes, strong needs for acceptance and low self-esteem can cause 'serious consequences'.

In a study of parents and professional views on Internet usage among young people with IDD. LöfgrenMårtenson, Sorbring and Molin (2015) report that young people with IDD in their study were looked upon as more vulnerable than other youth. Bjuis, Boot, Shugar, Fung, and Bassett $(2016$, p. 2) argue that because people with IDD 'have poor insight and judgement [..] they may therefore be at risk from internet dangers.' Chadwick et al. (2017) report the results of a survey in which non-disabled respondents perceived people with IDD to be more at risk of harm through their use of the Internet than non-disabled people.

Normand and Sallafranque St Louis (2016) conducted a literature review of the risk factors associated with online sexual solicitation. They found 57 published papers, but only two focusing on IDD. Despite this they concluded that the many of the risk factors (e.g. Ioneliness, depression, social isolation) are more prevalent in youth with IDD than the general population. One rare study on this topic is that reported by Didden et al. (2009), the results of which contradict to some extent the conclusions of Normand et al (2016). Didden et al. (2009) conducted a questionnaire survey of the prevalence of Internet and mobile phone cyber-bullying amongst a group of young people with IDD aged between 12 and 19. Key findings were that $90 \%$ of students were not involved in bullying via the Internet and that only $7 \%$ were victimized (We must note that both the Normand and Sallafranque St Louis review and the Didden et al. study included children under the age of 13, which does not accord with our original exclusion criteria, however, by also including participants over 13 , they do incorporate adolescents and adults and hence has been included in this review.)

There are examples cited in the literature of practitioners reporting actual cases where harm has come to people with IDD. For example, Holmes and O'Loughlin (2014) spoke to three women with IDD about their use of Facebook and noted that they had experienced being bullied online and having money taken from them. Buijs et al. (2017) present three composite case vignettes based on actual cases (although they fail to say how many actual cases they have witnessed and over what period of time the actual cases occurred). One vignette describes how a woman's online boyfriend convinces her to apply for multiple credit cards and sexually assaults her. Löfgren-Mårtenson et al. (2015) interviewed parents about their children's Internet use. They report how the young people with IDD in their study had a hard time understanding what is considered proper behaviour on the Internet and that it can be hard for them to: 'to predict the results of their actions on the Internet and to detect what is true about other people's intentions' (p.540). They note that responses to this perceived risk appear to be to apply restrictive strategies such as rules and threats rather than: 'giving more responsibility to the young people through information and education' (p.542).

There may be particular groups of people with IDD who may be more likely to agree to engage in risky behaviors online. For example, people with William's syndrome have been labeled as 'hyper-social', and survey based studies of 28 adults with William's syndrome found respondents to be more socially vulnerable in both the on and offline world (Lough \& Fisher, 2016a, b). The second linked study found that participants lacked insight into how things they do put them at risk which may make them more susceptible to victimization. Participants with William's syndrome also rated their vulnerability as lower than their carers. These studies advocate future intervention based research to support people with William's syndrome to better recognize and respond to risky situations.

There is evidence to show that some people with IDD may not necessarily be unaware of the risks of Internet use (Löfgren-Mårtenson, 2008; Bannon, McGlynn, McKenzie, \& Quayle. 2015). Bannon et al. (2015) reports the results of a focus group study conducted with 36 young people described as having 'additional support needs' designed to investigate their understanding of online risks. The results revealed that the young people were aware of a range of risks and had developed some strategies to manage these which often involved asking for support from adults or peers. The young people also reported some reluctance to disclose problems on the Internet in case this resulted in them losing access. 
There is also evidence to show that perceptions of risk vary between people with IDD, their parents and their support workers. For example: Löfgren-Mårtenson (2008) interviewed 10 young people with IDD and 12 staff members about their use of the Internet. The results revealed marked differences in risk perceptions. Whilst the young people with IDD were aware of the risks, they viewed the Internet as a positive arena where they could be 'like everybody else'. However, the staff worried considerably and focused mainly on the risks involved. LöfgrenMårtenson argued that the perceptions of staff were influenced by preconceptions of people with learning disabilities as 'gullible'. Löfgren-Mårtenson et al. (2015) report the results of a study aim to examine parents' and professionals' views on the usage of Internet for love and sexual purposes among young people with IDD (18-20 years) in Sweden. Results suggested that parents worried less about risks of Internet use than professionals. However, it is important to acknowledge that parents are not a homogenous group and views can vary. For example, Fiser (2012, p. 12) reports on the results of a survey of 3 parents regarding their children's' (young adults with Down Syndrome) use of social networks and noted: "In just three responses, there are a wide range of attitudes expressed towards online safety, from surveillance of online activity to general awareness of what is appropriate."

In making decisions about how risky Internet use for people with IDD is, there is some evidence that the perceived benefits of Internet use are balanced against the perceived risks (Bannon et al., 2015; Chadwick et al., 2017; Holmes \& O'Loughlin, 2014). Molin, Sorbring and Löfgren-Mårtenson, (2015, p. 24) for example note that: "These new virtual spaces create both opportunities and risks for users, especially when it comes to developing alternative identities that are not linked to common experiences of stigmatization and alienation". Thinking about the outcomes of balancing perceived benefits against perceived risk raises issues regarding what support workers perceive to be appropriate risk intervention strategies in relation to supporting Internet use by people with IDD.

\section{Perceptions of Appropriate Risk Intervention}

Our review of the literature reveals two main types of strategies aimed at mediating risk for adults with IDD: educative strategies and monitoring strategies. However, educative strategies are reported less frequently than monitoring strategies. This may be because our review set out to exclude studies of children, which is where the majority of educational research and practice tends to be reported. Or it may be because developing and implementing training programs around Internet use is both challenging and time, finance and labour intensive. An example of an educative strategy is that described by Holmes and O'Loughlin $(2014$, p.5) who set up a therapeutic support group for adults with IDD who had reported negative Internet experiences. The group focused on self-esteem, assertiveness training as well as specific Internet skills such as maintaining privacy skills.

Examples of monitoring strategies designed to mitigate or prevent harm include providing chaperones or supervisors (Slavin, 2002; McClimens \& Gordon 2009) For example, McClimens and Gordon (2009) examined the consequences of giving adults with IDD supported access to online blogs. They report how they offered training on issues such as using pseudonyms and withholding private information. Despite the training, participants' Internet use was still under of the direct supervision of 'student chaperones'. Neither Slavin or McClimens and Gordon elaborate on whether adults with learning disabilities were able to choose who they worked with or what guidance the chaperones were given regarding whether and how to intervene in online interactions. There is a silence therefore around the extent to which decisions regarding these chaperones were negotiated with the adults with IDD. It is not clear therefore whether Internet use in these cases is active or passive; or whether supervised Internet use is perceived as meaningful use by adults with IDD themselves. Questions such as these led Seale (2007) to question the extent to which the Internet could be a vehicle for self-advocacy for people with IDD if Internet use is overly mediated by powerful others.

Whilst it may be considered normal or appropriate for parents and other guardians to monitor the online activities of children we would argue that it is should not be considered as normal for them to monitor the activities of adults, even if they do have IDD. Furthermore, it highlights a discrepancy between societal norms and people's 'real' life. By over-scrutinizing and regulating people's online lives from a top-down 'societal' rather than a bottom up 'personal' perspective, adults with IDD are being held to different standards when compared with non-disabled adults. This arguably non-equivalent treatment leads to a situation of inequity. 


\section{Discussion}

In this paper we have reviewed current research and practice in the field of Internet use by adults with IDD. There have been two over-arching cross-cutting themes in this review: risk and normalcy. In conducting this review our aim has been to identify areas that require further investigation and to suggest conceptual lenses that might usefully frame future research.

\section{What Issues Need Further Research and How Might these Issues Be Researched?}

Our review of current research and practice in the field of Internet use by adults with IDD suggests a future research agenda that focuses on two main themes, namely: use and support. We propose that it is important to investigate further how adults with IDD are using or want to use the Internet as well as what support practices look like, what influences support and how might it be developed to enable a positive approach to the risks of Internet use for people with IDD (See Table 2). In addition we argue that a mixture of qualitative and quantitative methods are needed to illuminate the issues in more detail. In proposing the use of qualitative methods our position is that qualitative research is needed in order to capture the lived experience of both people with IDD and their support workers and to capture complex issues such as perceptions of risk and normalcy and how they intersect with issues relating to motivation, rights, and meaningfulness. Hence it will be important to employ a range of ethnographic, phenomenological and narrative methodologies. Furthermore, we argue that research in this field should employ inclusive or participatory methods (Nind, 2014) where people with IDD and their support workers are not the objects of academic gaze, but instead are co-researchers, working alongside academics to determine what questions are important to ask and how they should be answered.

\section{What Conceptual Lens Can Be Used to Frame Future Research?}

A number of conceptual lenses could be used to frame the design, implementation and analysis of future research in this field including a digital inclusion or a human rights framework. However, we would suggest that there is particular merit in exploring the extent to which a positive risk-taking framework might inform future research. Seale (2014) adapted the positive-risk taking framework proposed by Seale et al. (2012) and argued that it had relevance for thinking about how support workers facilitated access to a range of technologies, including the Internet, for people with IDD. She argued that a range of factors mediate whether and how positive-risk taking is implemented including: reasons for using the technology; the context in which the technology is being used; risk perceptions; nature of support role (e.g. parent; teacher; health and social care worker); previous non technology and technology related 'risk' experiences (positive and negative) and supportive environment (support from parents, managers, peers etc.). Seale argued that this framework could be useful in provoking certain kinds of questions that enable a more rigorous and insightful interrogation of the nature and quality of support provided to enable people with learning disabilities to use technologies.

The field of Internet use by people with IDD, with its underpinning tensions relating to normalcy and risk certainly needs provoking. Therefore we propose that with some adaptation and testing this framework could be a useful analytical tool in future research in the field. As a result of our review, we would include some additional influencing factors: perceptions of 'normalcy'; the extent to which it is culturally and socially accepted that living a normal life means using the Internet and perceptions regarding appropriate and meaningful Internet use (See Table 3). 
Table 2. A Future Agenda for Researching Internet Use by People with IDD.

\begin{tabular}{l} 
Theme \\
\hline USE \\
How people with IDD use \\
or want to use the \\
Internet
\end{tabular}

Focus

Identifying gradations of patterns of use and non-

use that are relevant to the lives of people with IDD

and which focuses on agency, mediation,

motivation and gratification

Understanding in detail what constitutes

meaningful Internet Use for people with IDD and

illuminating complex relationships between use,

risk and meaningfulness

Exploring how adults with IDD identify issues of risk and seek to problem-solve ways of managing the risks around using the Internet

Exploring the extent to which people's online lives exemplify particular relevant rights

Developing a model of online risks derived from the experiences of people with IDD which captures the nuances of risk perception and how this might influence different kinds of Internet use (gradations)

Developing and evaluating interventions which seek to educate and enable adults with IDD to better recognize and respond to risky situations.

Describing and examining in detail current support practices with a specific focus on: 1) The extent to which more motivated or agentic activities are tolerated and facilitated 2) What Internet activities support workers are more willing to facilitate

Investigating in detail the process of shared decision making around access to and use of the Internet and the facilitators and impediments to self-determination. This should include: 1) An exploration of how people with IDD and support workers negotiate meaningful use 2) an examination of the ways in which rights such as online freedom of expression are permitted or curtailed

Investigating the process of weighing up risks and benefits of Internet use by support workers including: what they perceive to be acceptable levels of risk and appropriate risk management strategies; and the genesis of different perceptions of levels of risk between people with IDD and those providing support

Developing and evaluating interventions for support workers focusing on how to facilitate shared decision making, how to educate and support people with IDD regarding positive risk taking
Proposed research methods

Adapted survey based studies (with

thorough piloting of measurement tools)

combined with ethnographic studies of Internet use

Phenomenological and narrative studies of the lived experiences of people with IDD in managing online risk and using the Internet

Phenomenological and narrative studies of experiences of being online.

Descriptive qualitative studies;

Longitudinal qualitative investigations of

processes and trajectories in Internet use;

Inclusive research to develop interventions and educational packages; Well defined quasi-experimental pre-post studies (e.g. multiple baseline/pre-post intervention with randomization and a waiting list control) to investigate the efficacy of the intervention

A combination of ethnographic studies of support in action along with phenomenological and narrative studies of support experiences.

More detailed qualitative studies of study gathering the lived experiences and perspectives of people with IDD and those providing support; Conversational analysis; Qualitative observational and ethnographic studies.

Descriptive and correlational survey based studies of risk perceptions; Interview based qualitative studies of the beliefs and experiences of those providing support.

Inclusive research to develop interventions and educational packages; Well defined quasi-experimental pre-post studies to investigate the efficacy of such interventions. 
Table 3. Scoping the Components of a Positive Risk Taking Framework in Relation to Supporting the Use of the Internet by People with IDD.

\begin{tabular}{lll}
\hline $\begin{array}{l}\text { Key components of positive } \\
\text { risk taking }\end{array}$ & Related components & $\begin{array}{l}\text { Potential Influencing } \\
\text { factors }\end{array}$ \\
\hline
\end{tabular}

\section{Shared decision-making \\ process: between people with \\ IDD and their support workers in \\ which both the potential positive \\ and negative outcomes of}

Internet use are considered.
Risk management: Putting in place strategies that attempt to mitigate the risks of Internet use, in the hope that there will be positive outcomes
Possibility-thinking: Identifying possibilities for

positive outcomes as a result of Internet use

Resilience: the decision regarding whether or not to use the Internet will be influenced by the extent to which people with IDD and their support workers believe that 1) people with IDD have the potential to be resilient or to live resilient lives 2) support workers have the potential professional skills and experience to be resilient

Possibility thinking: Refusing to give up when circumstances seem impossible. Using imagination to solve the 'problem' of how the risks related to using the Internet can be managed in order to maximize the possibilities for a positive outcome

Resilience: the chosen risk management strategy will be influenced by the extent to which support workers and people with IDD believe they have the ability to cope if using the technology in question does not result in the expected outcome
Reasons for using the Internet

Context in which the Internet is being used

Risk perceptions

Perceptions of 'normalcy'; the extent to which it is culturally and socially accepted that living a normal life means using the Internet

Perceptions regarding appropriate and meaningful Internet use Nature of support role (e.g. parent; teacher; health and social care worker, , peer, mentor)

Previous non Internet and Internet related 'risk' experiences (positive and negative)

Previous technology related experiences (positive and negative)

Supportive environment: support from parents, managers, peers etc.

\section{Conclusion}

In this paper we have reviewed existing literature in the field of Internet use and people with IDD. As a result of this review we argue that the identified gaps and problems need to be addressed by expanding both methodological and conceptual approaches to research in the field. In particular we argue that that new methodological approaches are required that: (i) extends the 'gaze' beyond people with IDD to include their support workers; (ii) examines in more detail the minutiae of the interactions between people with IDD, their support workers and the Internet; and (iii) enables people with IDD and their support workers to contribute their narratives and lived experiences of Internet use in ways that are meaningful, inclusive and empowering. We also propose that conceptualizations of risk and Internet use need to be problematized and re-examined in the context of the lives that people with IDD want to live. 


\section{References}

Alaszewski, A., \& Alaszewski, H. (2002). Towards the creative management of risk: Perceptions, practices and policies. British Journal of Learning Disabilities, 30, 56-62. https://doi.org/10.1046/j.1468-3156.2001.00153.x

Alquatani, H. H., \& Schoenfield, N. A. (2014). Teaching cooking skills to young women with mild intellectual disability: The effectiveness of Internet websites. Current Issues in Education, 17, 1-10.

Bannon, S., McGlynn, T., McKenzie, K., \& Quayle, E. (2015). The Internet and young people with additional support needs (ASN): Risk and safety. Computers in Human Behavior, 53, 495-503.

https://doi.org/10.1016/j.chb.2014.12.057

BECTA (2001). The digital divide: A discussion paper. Retrieved from

http://partners.becta.org.uk/page_documents/research/digitaldivide.pdf

Buijs P. C. M., Boot E., Shugar A., Fung W. L. A., \& Bassett A. S. (2016). Internet safety issues for adolescents and adults with intellectual disabilities. Journal of Applied Research in Intellectual Disabilities, 30, 416-418.

https://doi.org/10.1111/jar.12250

Butler, L., \& Bayne, H. (2000). Developing online resources for adults with intellectual disabilities. Paper presented at Networking 2000 Conference, Australia. Retrieved from

http://www.flexiblelearning.net.au/nw2000/talkback/p05.htm

Carey, A. C., Friedman, M., \& Bryen, D. N. (2005). Use of electronic technologies by people with intellectual disabilities. Mental Retardation, 43, 322-333.

Chadwick, D. D. (2016, June). Restriction, risk and reward? The digital inclusion of people with an intellectual disability (keynote presentation). Transitions Across the Life Course of People with Disabilities: Experiences, Opportunities and Strategies, Off- and Online. International Workshop, University of Umea, Sweden.

Chadwick D., Fullwood C., \& Wesson C. (2012). Intellectual disability, identity and the Internet. In: R. Luppicini (Ed.), Handbook of research on techno-self: Identity in a technological society (pp. 229-254). Hershey, PA: IGI Global.

Chadwick, D. D., Quinn, S., \& Fullwood, C. (2017). Perceptions of the risk and benefits of Internet access and use by people with intellectual disabilities. British Journal of Learning Disabilities, 45, 21-31.

https://doi.org/10.1111/bld.12170

Chadwick, D. D., Wesson, C., \& Fullwood, C. (2013). Internet access by people with intellectual disabilities: inequalities and opportunities. Future Internet - Special Issue "Inequality in the Digital Environment", 5, 376-397. https://doi.org/10.3390/fi5030376

Chadwick, D., \& Wesson, C. (2016). Digital inclusion and disability. In A. Attrill \& C. Fullwood (Eds.), Applied cyberpsychology: Practical application of cyberpsychological theory and research. Chennai, India: Palgrave Macmillan.

Davis, R. A., Flett, G. L., \& Besser, A. (2002). Validation of a new scale for measuring problematic Internet use: Implications for pre-employment screening. CyberPsychology \& Behaviour, 5, 331-345.

https://doi.org/10.1089/109493102760275581

Department of Health. (2005). Independence, well-being and choice: Our vision for the future of social care for adults in England. London: HMSO.

Didden, R., Scholte, R. H. J., Korzilius, H., DeMoor, J. M. H., Vermeulen, A., O'Reilly, M., Lang, R., \& Lancioni, G. E. (2009). Cyberbullying along students with intellectual and developmental disability in special education settings. Developmental Neurorehabilitation, 12, 146-151. https://doi.org/10.1080/17518420902971356

Fiser, K. (2012). Parental perspectives on young adults with Down syndrome and online social networking sites (2012). Rehabilitation, Human Resources and Communication Disorders Undergraduate Honors Theses. Paper 9.

Goodley, D. (2005). Empowerment, self-advocacy and resilience, Journal Intellectual Disabilities, 9, 333-343. https://doi.org/10.1177/1744629505059267 
Grant, M. J., \& Booth, A. (2009). A typology of reviews: An analysis of 14 review types and associated methodologies. Health Information and Libraries Journal, 26, 91-108. https://doi.org/10.1111/j.14711842.2009.00848.x

Hegarty, J. R. (1998). INTERCHANGE - promoting international friendship-links for people with intellectual impairment. In I. Placencia-Porrero \& E. Ballabio (Eds.), Improving the quality of life for the European Citizen (pp. 179-184). Amsterdam: IOS Press.

Holmes, K. M., \& O'Loughlin, N. (2014). The experiences of people with learning disabilities on social networking sites. British Journal of Learning Disabilities, 42, 1-5. https://doi.org/10.1111/bld.12001

Jaeger, P. T. (2015). Disability, human rights, and social justice: The ongoing struggle for online accessibility and equality. First Monday, 20, 9. Retrieved from:

http://firstmonday.org/ojs/index.php/fm/rt/printerFriendly/6164/4898

Jay, P. (1979). Report of the Committee Enquiry into Mental Handicap Nursing and Care. London: HMSO.

Jerome, J., Frantino, E., \& Sturmey, P. (2007). The effects of errorless learning and backward chaining on the acquisition of Internet skills in adults with intellectual disabilities. Journal of Applied Behavioural Analysis, 40, 185189. https://doi.org/10.1901/jaba.2007.41-06

Johnson, R., \& Hegarty, J.R. (2003).Websites as educational motivators for adults with learning disability. British Journal of Educational Technology, 34, 479-486. https://doi.org/10.1111/1467-8535.00344

Katz, E., Blumler, J., \& Gurevitch, M. (1974). Utilization of mass communication by the individual. In J. Blumler \& E. Katz (Eds.), The uses of mass communication: Current perspectives on gratifications research (pp. 19-34). Beverly Hills, CA: Sage.

Kydlund, F. K., Molka-Danielson, J., \& Balandin, S. (2012). Examining the use of social media tool "Flickr" for impact on loneliness for people with intellectual disability. In NOKOBIT 2012 : Proceedings of the 2012 Norsk konferanse for organisasjoners bruk av informasjonsteknologi (pp. 253-264). Retrieved from:

http://dro.deakin.edu.au/view/DU:30062177

Livingston, S., \& Haddon, L. (2009). EU Kids Online final report. LSE, London: EU Kids Online.

Livingstone, S., Mascheroni, G., \& Staksrud, E. (2015). Developing a framework for researching children's online risks and opportunities in Europe. LSE, London: EU Kids Online. Retrieved from: http://eprints.Ise.ac.uk/64470/

Löfgren-Mårtenson, L. (2008). Love in cyberspace: Swedish young people with intellectual disabilities and the Internet. Scandinavian Journal of Disability Research, 10, 125-138. https://doi.org/10.1080/15017410701758005

Löfgren-Mårtenson, L., Sorbring, E., \& Molin, M. (2015) “T@ngled up in Blue”: Views of parents and professionals on Internet use for sexual purposes among young people with intellectual disabilities. Sex Disabil, 33, 533-544. https://doi.org/10.1007/s11195-015-9415-7

Lough, E., \& Fisher, M.H. (2016a). Internet use and online safety in adults with Williams syndrome. Journal of Intellectual Disability Research, 60, 1020-1030. https://doi.org/10.1111/jir.12281

Lough, E., \& Fisher, M. (2016b). Parent and Self-Report Ratings on the Perceived Levels of Social Vulnerability of Adults with Williams Syndrome. Journal of Autism and Developmental Disorders, 46, 3424-3433.

https://doi.org/10.1007/s10803-016-2885-3

McClimens, A., \& Gordon, F. (2009). People with intellectual disabilities as bloggers: What's social capital got to do with it anyway? Journal of Intellectual Disabilities, 15, 19-30. https://doi.org/10.1177/1744629509104486

Milner, P., \& Mirfin-Veitch, B. (2012). "I am here": The Article 19 Project. CCS Disability Action \& Donald Beasley Institute.

Moisey, S. D. (2001). Virtual community for adults with developmental disabilities and their families. International Review of Research in Open and Distance Learning, 2(1). Retrieved from:

http://www.irrodl.org/index.php/irrodl/article/view/39/68 
Moisey, S., \& van de Keere, R. (2007). Inclusion and the Internet: Teaching adults with developmental disabilities to use Information and Communication Technologies. Developmental Disabilities Bulletin, 35, 72-102.

Molin, M., Sorbring, E., Löfgren-Mårtenson, E. (2015). Teachers' and parents views on the Internet and social media usage by pupils with intellectual disabilities. Journal of Intellectual Disabilities, 19, 22-23.

https://doi.org/10.1177/1744629514563558

Morgan, S. (2004, October). Positive risk taking: An idea whose time has come. Health Care Risk Report. Retrieved from: http://static1.1.sqspcdn.com/static/f/586382/9538512/1290507680737/OpenMind-

PositiveRiskTaking.pdf?token=EIVKhX4Soz6TIFbuppAGcJTsZVI\%3D

Näslund, R., \& Gardelli, A. (2013). 'I know, I can, I will try': Youths and adults with intellectual disabilities in Sweden using information and communication technology in their everyday life. Disability and Society, 28, 28-40. https://doi.org/10.1080/09687599.2012.695528

Nind, M. (2014). What is Inclusive Research? London: Bloomsbury Academic.

Normand, C. L., \& Sallafranque St Louis, F. (2016) Cybervictimisation of young people with an intellectual or developmental disability: Risks specific to sexual solicitation. Journal of Applied Research in Intellectual Disabilities, 29, 99-110. https://doi.org/10.1111/jar.12163

Perske, R. (1972). The dignity of risk. In: W. Wolfensberger., B. Nirje., S. Olansky., R. Perske, \& P. Roos (Eds.), The principles of normalization in human services. Toronto: National Institute on Mental Retardation through Leonard crainford.

Plichta, P. (2011). Ways of ICT usage among mildly intellectually disabled adolescents. In E. Dunkels, G.-M. Franberg, \& C. Hallgren (Eds.), Youth culture and net culture: Online social practices (296-315). Hershey, PA: IGI Publishing.

Rocha, T., Bessa, M., Magalhaes, L., \& Cabral, L. (2015, September). Performing universal tasks on the Web: Interaction with digital content by people with intellectual disabilities. Paper presented at Interaccion '15, Barcelona, Spain.

Ruggerio, T. E. (2000). Uses and gratifications theory in the 21st century. Mass Communication and Society, 3, 3-37. https://doi.org/10.1207/S15327825MCS0301_02

Schindler, P., \& Borchardt, K. (2001, October). "I want that!" --teaching the internet and email to a group of clients with intellectual disability. Paper presented at the Reference and Information Services Section Symposium (RAISS).

Retrieved from: http://www.library.uq.edu.au/papers/confpaper.doc

Seale, J. K. (2001). The same but different: The use of the personal home page by adults with Down syndrome as a tool for self-presentation. British Journal of Educational Technology, 32, 343-352. https://doi.org/10.1111/14678535.00203

Seale, J. K., \& Pockney, R. (2002). The use of the personal home page by adults with Down syndrome as a tool for managing identity and friendship. British Journal of Learning Disabilities, 30,142-148.

https://doi.org/10.1046/j.1468-3156.2002.00195.x

Seale, J. (2007). Strategies for supporting the online publishing activities of adults with learning difficulties. Disability and Society, 22, 173-186. https://doi.org/10.1080/09687590601141626

Seale, J., Nind, M., \& Simmons, B. (2013). Transforming positive risk taking practices: The possibilities of creativity and resilience in learning disability contexts. Scandinavian Journal of Disability Research, 15, 233-248.

https://doi.org/10.1080/15017419.2012.703967

Seale, J. (2014). The role of supporters in facilitating use of technologies by adolescents and adults with learning disabilities: A place for positive risk taking? European Journal of Special Needs Education, 29, 220-236.

https://doi.org/10.1080/08856257.2014.906980

Selwyn, N. (2006) Digital division or digital decision? A study of non-users and low-users of computers. Poetics: Journal of Empirical Research in Culture, Media and the Arts, 34, 273-292.

https://doi.org/10.1016/j.poetic.2006.05.003 
Selwyn, N., \& Facer. K (2007). Beyond the digital divide: Rethinking digital inclusion for the $21^{\text {st }}$ century. Bristol: FutureLab. Retrieved from:

http://www.futurelab.org.uk/resources/documents/opening_education/Digital_Divide.pdf

Shpigelman, C.-N., \& Gill, C. J. (2014). How do adults with intellectual disabilities use Facebook? Disability \& Society, 29, 1601-1616. https://doi.org/10.1080/09687599.2014.966186

Slavin, M. (2002). The Homepage Project. Retrieved from: http://www.ckglasgow.org.uk/homepageproject/

Stendal, K., Molka-Danielson, J., Munkvold, B. E., \& Balandin, S. (2011). Initial experience with virtual worlds for people with lifelong disability: Preliminary findings. In NOKOBIT 2011: Proceedings of the 2011 Norsk konferanse for organisasjoners bruk av informasjonsteknologi (pp. 105-118). Retrieved from:

http://dro.deakin.edu.au/view/DU:30062167

Turel, O., \& Serenko, A. (2012). The benefits and dangers of enjoyment with social networking websites. European Journal of Information Systems, 21, 512-528. https://doi.org/10.1057/ejis.2012.1

UN General Assembly. (2006). Convention on the Rights of Persons with Disabilities. Retrieved from:

http://www.un.org/disabilities

Vanden Abeele, M., de Cock, R., \& Roe, K. (2012). Blind faith in the web? Internet use and empowerment among visually and hearing impaired adults: A qualitative study of benefits and barriers. Communications, 37, 129-151. https://doi.org/10.1515/commun-2012-0007

Watson, J. (2016). Assumptions of decision-making capacity: The role supporter attitudes play in the realisation of article 12 for people with severe or profound intellectual disability.

Laws, 5(1), 6. Retrieved from: https://doi.org/10.3390/laws5010006

Williams, P. (2006). Developing methods to evaluate web usability with people with learning difficulties. British Journal of Special Education, 33, 173-179. https://doi.org/10.1111/j.1467-8578.2006.00436.x

Williams, P. (2011). Barriers to the creation and use of an accessible web portal for people with learning disabilities. International Journal of Education, 3(2), E21. https://doi.org/10.5296/ije.v3i2.1283

Wolfensberger, W., Nirje., B., Olansky, S., Perske., R., \& Roos, P. (1972). The principles of normalization in human services. Toronto: National Institute on Mental Retardation through Leonard Crainford.

Zubal-Ruggieri, R. (2015). Making links, making connections: Internet resources for self-advocates and people with developmental disabilities. Intellectual and Developmental Disabilities, 45, 209-2015.

https://doi.org/10.1352/1934-9556(2007)45[209:MLMCIR]2.0.CO;2

\section{Correspondence to:}

Professor Jane Seale

Faculty of Well-being, Education and Language Studies

The Open University

Walton Hall

Milton Keynes, MK7 6AA

United Kingdom

Email: jane.seale@open.ac.uk 


\section{About Authors}

Dr Jane Seale is Professor of Education at The Open University, United Kingdom. Her research interests are related to learning disability, technology and inclusion.

Dr Darren Chadwick is a Reader in Applied Psychology at the University of Wolverhampton. His research interests are related to developmental psychology, people with intellectual and developmental disabilities and Internet use.

Editorial record: First submission received on September 11, 2016. Revision received on January 4, 2017. Accepted for publication on May 5, 2017. The article is part of Special Issue "Internet use and disability - Risks, opportunities and challenges" guest edited by Emma Sorbring and Martin Molin. 